\title{
Memória conventual e política em Portugal no Antigo Regime*
}

\author{
Lígia Bellini
}

\author{
Moreno Laborda Pacheco ${ }^{3}$
}

O artigo examina vínculos envolvendo conventos, famílias nobres e a Corte em Portugal, que emergem do estudo de crônicas monásticas datadas dos séculos XVII e XVIII. Tais vínculos incluem o ingresso de membros dessas famílias nos mosteiros, manifestações de fidelidade política por parte das comunidades religiosas e favores da nobreza a elas, entre outras práticas. A partir das crônicas, é possível explorar os modos como as comunidades se posicionaram com respeito a transformações nas esferas de poder. Palavras-chave: memória conventual, política, Portugal, séculos XVII e XVIII.

\section{Monastic memory and politics in Portugal in the Ancien Régime}

The article examines links involving Portuguese convents, noble families and the court, which emerge from the study of chronicles of these monastic houses written in the seventeenth and eighteenth centuries. Such links include the presence of members of these families in the monasteries, demonstrations of political allegiances by the religious communities, as well as favours from the nobility to them, among other practices. Monastic chronicles are suitable sources to investigate the ways in which the communities positioned themselves as regards changes in the political sphere. Keywords: monastic memory, politics, seventeenth and eighteenth-century Portugal.

\footnotetext{
* O presente artigo foi escrito com base em pesquisas financiadas pela Capes (estágio sênior no exterior: King's College London) e CNPq (bolsas de produtividade em pesquisa, da primeira autora, e doutorado, do segundo autor).

${ }^{1}$ Artigo recebido em /6/2011 e aprovado 5/6/2011.

${ }^{2}$ Professora Doutora da Universidade Federal da Bahia.

${ }^{3}$ Doutorando no Programa de Pós-Graduação em História da Universidade Federal da Bahia.
} 


\section{Mémoire conventuelle et politique au Portugal d'Ancien Régime}

À partir de létude de quelques chroniques monastiques des XVII et XVIII ${ }^{e}$ siècles, cet article présente une analyse des liens entre des couvents, des familles de la noblesse et la cour au Portugal. Ces liens comprennent, entre autres choses, l'admission de membres de la noblesse dans les couvents, des manifestations de fidélité politique de la part des communautés religieuses ainsi que des faveurs qui leurs étaient accordées par la noblesse. À partir de ces chroniques, il est possible d'explorer les moyens par lesquels ces communautés ont pris position à l'égard des changements dans les sphères du pouvoir. Mots-clés: mémoire conventuelle, politique, Portugal aux XVII et XVIII ${ }^{e}$ siècles.

Nos séculos XVII e XVIII, produziu-se em Portugal um número apreciável de crônicas ou histórias ${ }^{4}$ versando sobre mosteiros femininos e masculinos, a partir das quais é possível explorar, entre outros temas, formas de sociabilidade e vivências religiosas no interior das casas, ideais de virtude e santidade, práticas da escrita e relações de gênero. ${ }^{5}$ Esses textos também trazem uma diversidade de informações sobre vínculos, negociações e por vezes conflitos envolvendo os conventos e províncias, a nobreza e a corte, relações das quais a própria escrita das crônicas pode ser considerada parte integrante. Crônicas conventuais, que discorrem sobre a trajetória histórica das comunidades no decorrer de longos períodos, sobre eventos relevantes a elas relacionados e sobre biografias de membros veneráveis, evidenciam os modos pelos quais elas se posicionaram diante de transformações nas esferas de poder.

\footnotetext{
${ }^{4}$ Não há um padrão estabelecido quanto às denominações que os autores dão aos seus escritos. Os termos "crônica", "história", "tratado" e "notícia" são em geral usados como equivalentes e intercambiáveis, fato também observado por Kate Lowe em seu estudo sobre crônicas conventuais femininas na Itália moderna. LOWE, K. Nuns' chronicles and convent culture in Renaissance and Counter-Reformation Italy. Cambridge: Cambridge University Press, 2003. cap. 1. É preciso notar, no entanto, que formulações encontradas em diversas crônicas religiosas setecentistas indicam uma valorização da história como superior às demais formas. Uma discussão das concepções estabelecidas no meio historiográfico moderno, as quais discriminam três tipos básicos de representação histórica - anais, crônicas e histórias - tendo como referência seu grau de "narratividade", encontra-se em WHITE, Hayden. The value of narrativity in the representation of reality. Critical Inquiry, Chicago, v. 7, n. 1, “On Narrative", p. 5-27, outono 1980.

${ }^{5}$ Ver BELLINI, Lígia; PACHECO, Moreno Laborda. Experiência e ideais de vida religiosa em mosteiros portugueses clarianos, nos séculos XVII e XVIII. Revista de História (USP), São Paulo, v. 160, p. 147-167, 2009; e BELLINI, Lígia. Cultura escrita, oralidade e gênero em conventos portugueses (séculos XVII e XVIII). Tempo, Rio de Janeiro, v. 29, p. 211-233, 2010.
} 
São aqui focalizadas duas memórias de conventos femininos e duas histórias de uma província, todas casas pertencentes ao ramo franciscano observante: os manuscritos Tratado da antiga e curiosa fundação do Convento de Jesus de Setúbal, escrito entre 1630 e 1644 pela madre Leonor de São João, e Notícia da fundação do Convento da Madre de Deus das religiosas descalças de Lisboa, obra apócrifa composta entre 1639 e 1652; ${ }^{6}$ e os tratados publicados Espelho de penitentes, e chronica da provincia de Santa Maria da Arrabida (1728), de Antonio da Piedade, e sua sequência, com virtualmente o mesmo título, de autoria de Joseph de Jesus Maria, cuja publicação data de 1737 . $^{7}$

O Tratado de Setúbal compõe-se de cinco partes, as quais discorrem sobre episódios relativos à fundação do mosteiro, os ritos e práticas no dia a dia no seu interior, as relíquias e outras "coisas notáveis" lá existentes, as vidas exemplares de religiosas e ocorrências relevantes durante os abadessados. Esse ordenamento da escrita se dilui, no final, com a inclusão de alguns capítulos que não estavam previstos inicialmente, ${ }^{8}$ contendo diversas matérias. Trata-se, dessa forma, de uma obra aberta, que podia receber acrescentamentos posteriores, característica possibilitada pela forma manuscrita. Embora não tenha chegado a ser impresso, o Tratado recebeu as licenças necessárias para publicação. O manuscrito traz, logo nas primeiras folhas, os pareceres do ministro provincial dos Algarves e de outro parecerista por ele designado, o que parece expressar o endosso das instâncias superiores da ordem franciscana local para que fosse levado ao prelo. Recorre também a outro expediente de praxe para os autores que buscavam as casas tipo-

\footnotetext{
${ }^{6}$ Diogo Barbosa Machado, na compilação de autores portugueses que produziu no século XVIII, atribui a obra a Maria do Sacramento. Biblioteca lusitana histórica, crítica e cronológica. 2. ed. Lisboa: Academia Real da História Portuguesa, 1930-1934. 4 v., t. 3, p. 423. Outros autores supõem uma autoria tripla, de Catarina das Chagas, Joanna da Piedade e Margarida da Trindade. Ver SOUSA, Ivo Carneiro de. Rainha D. Leonor (1458-1525). Poder, misericórdia, religiosidade e espiritualidade no Portugal do Renascimento. Lisboa: Calouste Gulbenkian, 2002. p. 499-500.

${ }^{7}$ PIEDADE, Antonio da. Espelho de penitentes, e chronica da Provincia de Santa Maria da Arrabida da regular, e mais estreita observancia da Ordem do Serafico Patriarca S. Francisco, no Instituto Capucho. Lisboa: Joseph Antonio da Sylva, Impressor da Academia Real, 1728. t. I; MARIA, Joseph de Jesus. Espelho de penitentes, e chronica de Santa Maria da Arabida em que se manifestam as vidas de muntos santos varoens de abalizadas virtudes, e outros que pella verdade da Fé sacrificàrã as vidas destribuidas por todos os dias do anno. Lisboa Occidental: Officina de Joseph Antonio da Sylva, Impressor da Academia Real, 1737.

${ }^{8} \mathrm{O}$ índice lista até o capítulo XVII da quinta parte, que trata do abadessado da própria autora, durante o qual ela afirma que concluiu o livro. Esse abadessado teria se encerrado em 1631, mas os registros adicionais incluem notícias relativas a até 1641 .
} 
gráficas do Antigo Regime, qual seja, a dedicatória a uma figura ilustre - no caso, o marquês de Ferreira, D. Francisco de Melo (1588-1645). ${ }^{9}$

A Notícia sobre o Convento da Madre de Deus tem características que a distinguem do Tratado e dos dois volumes da crônica da Arrábida. Em primeiro lugar, foi escrita na forma de diálogos, e não em prosa. A autora do livro como um todo, ou a que escreveu sua parte inicial, declara que teria reproduzido conversas de fato havidas entre as sórores em encontros no período do Natal de 1638, chamados "fogueiras". Ainda que, à primeira vista, não fique evidente um plano geral do escrito, é possível detectar certo ordenamento temático que o aproxima do Tratado sobre o Convento de Setúbal. ${ }^{10}$ É dito no texto que as conversas narradas no penúltimo e último capítulos tiveram lugar em outros anos, 1644 e 1652, respectivamente. Se isso de fato ocorreu, a Notícia, assim como o Tratado de Leonor de São João, constitui exemplo de obra aberta. Diferentemente deste último, a Notícia não possui licenças para impressão e tampouco está dedicada a algum possível patrono de sua vinda ao lume. Parece dirigir-se apenas às demais religiosas do convento, com o intuito de imortalizar os exemplos edificantes de outras irmãs mais antigas que o tempo insistia em nublar da memória da casa. Se nos fiarmos na crônica do frei Jerônimo de Belém, a Notícia de fato nunca "saiu da clausura". ${ }^{11}$

O Espelho de penitentes, e chronica da provincia de Santa Maria da Arrabida, de Antonio da Piedade, é, como indica o título, uma narrativa dos acontecimentos considerados mais relevantes na história da província da Arrábida, desde seus inícios, em 1539, até as primeiras décadas do século XVII. No tom apologético e mitificante característico do gênero, versa sobre os vários conventos pertencentes à província, inclusive missões no ultramar, exaltando os ideais de perfeição evangélica da ordem, as virtudes de seus membros, assim como a devoção dos portugueses, em especial dos nobres, para com eles. Sua sequência, escrita por Joseph de Jesus Maria, centra-se nas biografias dos "varões santos", organizadas de acordo com os dias do ano em que os biografados faleceram, embora também

\footnotetext{
${ }^{9}$ No texto, o marquês é referido como "Dom Francisco Pereira de Castro, Marquês de Ferreira, Conde de Tentugal [...]".

${ }^{10}$ PACHECO, Moreno Laborda. Quando as freiras faziam história: crônicas conventuais, autoria feminina e poder em Portugal no século XVII. Anais do Simpósio Nacional de História - Anpuh, História e ética, p. 6, jul. 2009.

${ }^{11}$ MACHADO, Diogo Barbosa. Biblioteca lusitana... Op. cit., t. 3, p. 423.
} 
narre a celebração dos capítulos provinciais, a fundação de novos conventos e mesmo, eventualmente, conflitos em que a província esteve envolvida. Do ponto de vista cronológico, estende-se de 1623 até a época da composição da crônica, "pela ordem dos anos", conforme anuncia o autor no proêmio do livro.

Mesmo que não haja referências diretas que apontem para uma divulgação mais ampla das crônicas manuscritas, em especial da Notícia do Convento da Madre de Deus, todas as obras aqui enfocadas se encaixam na caracterização de Leila Algranti desses textos como públicos e domésticos/privados ao mesmo tempo. Ou seja, eles tinham uma faceta doméstica e privada, na medida em que preservavam a memória da instituição para os próprios habitantes da casa, e outra pública, pois nesses casos "sempre houve a intenção, mesmo camuflada, de enaltecer a ordem e divulgar a exemplaridade das 'vidas' fora dos conventos". ${ }^{12}$ As crônicas também parecem ter constituído instrumentos por meio dos quais os mosteiros negociavam e registravam benesses das elites políticas para essas casas religiosas, assim como davam a conhecer as relações de proximidade que mantinham com membros dessas elites.

Quer se destinassem a um público amplo, quer ao consumo interno, os textos memorialísticos realizam uma operação de recorte, seleção e mesmo idealização dos fatos que mereciam, na opinião dos seus autores, entrar para o registro. Estes demonstram ter consciência de que inscrever uma história no papel é também demarcar um perfil das instituições, criar para elas uma trajetória e alianças que se quer preservar. Assim, pode-se dizer que as narrativas não constituem exatamente tentativas de construir relatos fidedignos do passado, ficando evidente, como será discutido adiante, a vinculação de seus conteúdos com o lugar ocupado pelos autores e seus conventos nos diferentes contextos em que foram escritas. Deve-se observar, ainda, que elas, em larga medida, se estruturam segundo o que Diogo Ramada Curto caracterizou como "um modo específico de pensar socialmente a política baseada $[s i c]$ na referência individualizada dos nomes e das pessoas, ou seja, numa lógica da nomeação". ${ }^{13}$

\footnotetext{
${ }^{12}$ ALGRANTI, Leila Mezan. Livros de devoção, atos de censura: ensaios de história do livro e da leitura na América portuguesa (1750-1821). São Paulo: Hucitec/Fapesp, 2004. p. 60.

${ }^{13}$ CURTO, Diogo Ramada. A Restauração de 1640: nomes e pessoas. Península. Revista de Estudos Ibéricos, Porto, n. 0, p. 321-336 [p. 336], 2003.
} 
Ligações entre as casas monásticas e setores dominantes da sociedade ibérica já são perceptíveis nas dedicatórias das obras publicadas e da que almejava publicação. O marquês de Ferreira D. Francisco de Melo, a quem, como foi dito, é dedicado o tratado sobre o convento de Setúbal, era membro da casa de Bragança e associado por casamento à fidalguia espanhola. Mais que eventualmente possibilitar a publicação do livro de Leonor de São João, era um patrono e mediador potencial importante nas relações do Convento de Jesus com os centros políticos peninsulares. Ambas as crônicas da Arrábida foram dedicadas ao rei D. João V, cujo reinado estendeu-se de 1707 a 1750. No seu Espelho de penitentes, Antonio da Piedade manifesta o reconhecimento da província pela "proteção e patrocínio" que esta havia recebido dos pais do soberano, e continuava recebendo da sua "benigna e Real mão". Igual reconhecimento é registrado por Joseph de Jesus Maria, ao afirmar o amparo e favores dos reis de Portugal não só para com os franciscanos, mas também para as demais ordens religiosas do reino. $\mathrm{O}$ autor ainda roga ao monarca que "atenda" à província "com legítimo amor de pai para cuidar nos seus aumentos em todo o sentido considerados".

Outro aspecto indicativo das relações aqui discutidas emerge de um exame, ainda que ligeiro, do perfil socioeconômico das mulheres e homens ingressados nas casas. Não é possível, a partir unicamente das crônicas, construir um quadro extensivo desse perfil, dado que só há nelas registro mais detalhado de indivíduos que se destacaram por suas virtudes ou pela liderança que exerceram. Além deles, os textos citam nomes que aparecem apenas de passagem, como coadjuvantes em narrativas sobre ocasiões especiais e outras personagens mais importantes. Em que pesem essas lacunas, pode-se, com certa segurança, afirmar que os mosteiros cujas trajetórias são relatadas nesses escritos abrigavam um número significativo de freiras e frades oriundos de famílias nobres do reino. Na narrativa sobre o Convento de Jesus de Setúbal, cerca de metade das quase 200 irmãs mencionadas foi qualificada como pertencente à nobreza. Considerando-se as religiosas citadas nas crônicas de ambos os conventos femininos em conjunto, o percentual de ingressadas com tais origens é em torno de $30 \%{ }^{14}$ Ivo Carneiro de Sousa nota que era comum a procura do Convento da Madre de Deus por viúvas da nobreza,

\footnotetext{
${ }^{14} \mathrm{Na}$ Notícia sobre o convento da Madre de Deus, são citadas 86 religiosas.
} 
que lá pediam asilo após a morte de seus maridos. ${ }^{15} \mathrm{~A}$ referência a origens ilustres parece constituir credencial importante na representação dos mosteiros. Isso se manifesta, por exemplo, no fato de Leonor de São João se apresentar como de ascendência nobre ao dirigir-se ao patrono a quem sua obra é dedicada. Também os cronistas da Arrábida fazem menção frequente aos laços familiares dos religiosos biografados com a fidalguia. Alguns teriam inclusive desempenhado funções na corte, antes de ingressar na província. Frei Inocêncio do Rosário $(\dagger 1657)$ teria sido Moço da Câmara del Rey. Um amigo seu, que tomou o nome de frei Manoel de São Francisco (†1645), tinha o cargo de escrivão dos Contos. ${ }^{16}$ Frei António das Chagas (1558-1648) é referido como tendo sido Moço da Câmara do Rei D. Sebastião. ${ }^{17}$

Para além das relações familiares, as histórias referem-se recorrentemente a diversos tipos de proximidade entre as casas religiosas e figuras das elites políticas. As memórias dos conventos de Jesus de Setúbal e da Madre de Deus em Xabregas documentam a estreita relação dessas casas com o poder monárquico e os benefícios, inclusive econômicos, que disso resultavam. Destacam a participação dos reis nos primeiros tempos de criação dos mosteiros, na aquisição dos terrenos necessários, na emissão das autorizações papais para as fundações, na chegada das primeiras irmãs. Em Setúbal, D. João II (que reinou de 1481 a 1495) teria visitado o canteiro de obras durante um evento solene e, insatisfeito com seu atraso, teria sugerido mudanças no projeto; em Xabregas, a rainha D. Leonor (1458-1525) teria escolhido o local da construção, supervisionado as obras e ainda acompanhado a rotina das freiras, provendo-as do que fosse necessário. A preocupação dos reis com o andamento dos monastérios ultrapassa, nas crônicas, o tempo das fundações, atravessando diversos reinados e resultando em benesses as mais diversas: reformas dos claustros, doações de relíquias e imagens de devoção, intercessões junto a Roma, isenção do pagamento de certos tributos. Ao tempo que reduzia os gastos dos erários conventuais, a intervenção do soberano podia aumentá-los significativamente, aumentando, por exemplo, a

\footnotetext{
${ }^{15}$ SÃO JOÃO. Tratado..., fol. 30; SOUSA, Ivo Carneiro de. Rainha D. Leonor (1458-1525). Poder, misericórdia... Lisboa: Fundação Calouste Gulbenkian, 2002. p. 493.

${ }^{16}$ MARIA, Jesus. Espelho de penitentes..., p. 190.

${ }^{17}$ MARIA, Jesus. Espelho de penitentes..., p. 209-211. Não se trata do poeta e pregador cujas datas de nascimento e morte são respectivamente 1631 e 1682, e que em 1662 ingressou na província franciscana dos Algarves.
} 
atração dos fiéis para essas casas e o recebimento de esmolas e doações as mais diversas. ${ }^{18}$ Além disso, era o poder régio que também determinava a amplitude da atuação dos procuradores e mamposteiros dos conventos. Estes tinham papel central na arrecadação de doações, uma vez que, munidos da autorização necessária, podiam realizar seu trabalho em diversas vilas fora da localidade original da comunidade. ${ }^{19}$

Muitos outros patronos nobres - chamados padroeiros nas memórias - são mencionados como tendo provido sustento material e muitas vezes político, doando propriedades e bens necessários para a subsistência, promovendo a construção e a reforma de edifícios, participando das decisões e representando as casas junto a instâncias do governo secular e eclesiástico. O duque de Aveiro, D. João de Lencastre (1501-1571), patrocinou a fundação do primeiro convento e da então custódia da Arrábida, doando as terras na serra, obtendo as licenças para sua criação e mesmo recrutando membros compatíveis com o ideal de austeridade da comunidade que se formava. Entre inúmeras intervenções, a crônica de Antonio da Piedade registra sua atuação representando a custódia em disputas com o provincial dos Algarves, que desejava incorporá-la a essa província. Após sua morte, seu filho D. Jorge assumiu o papel de padroeiro. ${ }^{20} \mathrm{~A}$ par de atribuições semelhantes, a figura do infante D. Luís (1506-1555) é caracterizada como a de alguém com especial zelo pelos princípios que regiam os observantes arrábidos. ${ }^{21}$ Outro exemplo de atuação de um padroeiro é o de Lourenço Pires de Távora (1510-1573). Quando embaixador de Portugal em Roma, Távora teria obtido breve papal concedendo estatuto especial, no que respeita à obtenção de graças pelos fiéis, à igreja do Convento de Caparica, cuja fundação (1558) havia patrocinado. Em 1560, intermediou as negociações, junto ao papa Pio IV, que resultaram na elevação da custódia à província da Arrábida. ${ }^{22}$ Ainda, Pedro Vieira da Silva, que foi secretário de Estado de 1642 a 1656, patrocinou a fundação do Convento de Santo Antônio, em Leiria, no período de 1651 a $1657 .{ }^{23}$

\footnotetext{
${ }^{18}$ SOUSA. Rainha D. Leonor..., p. 493.

${ }^{19}$ SÃO JOÃO. Tratado..., fol. 58.

${ }^{20}$ PIEDADE. Espelho de penitentes..., livro I, cap. IV, VIII-XI, XIV-XV.

${ }^{21}$ PIEDADE. Espelho de penitentes..., livro I, cap. XXVII e XXVIII.

${ }^{22}$ PIEDADE. Espelho de penitentes..., livro II, cap. III; livro III, cap. I.

${ }^{23}$ MARIA, Jesus. Espelho de penitentes..., p. 267-277.
} 
O relacionamento dos religiosos com indivíduos e famílias ilustres é apresentado com frequência como um vínculo de natureza pessoal, fundado nas virtudes espirituais dos primeiros, em sua capacidade de mediar o recebimento de graças e de aconselhar, muitas vezes em questões políticas. Além de ter sido patrono da província, é dito de D. Diogo da Silva, quinto conde de Portalegre (1579-1640), que, tendo renunciado a suas atividades "no governo [do] Reino", "gastava o mais do tempo" nos conventos da Arrábida, em especial no de São Joseph de Ribamar, onde foi sepultado. ${ }^{24}$ Ainda a título de exemplo, segundo Joseph de Jesus Maria, frei Pedro de Mera ( $† 1632)$, por suas "letras, e virtudes", era "procurado, e consultado dos maiores Príncipes da Corte”. O frei era também confessor do arcebispo de Lisboa D. Miguel de Castro (1536-1625). ${ }^{25}$ Frei Mathias da Madre de Deus (1560-1643) também aconselhava nobres, entre outros, D. Luiz de Lencastre, comendador-mor de Avis (c. 1540-1613), a rainha D. Luiza de Gusmão (1613-1666) e o rei D. João IV (que reinou de 1640 a 1656). Frei Mathias teria chegado a advogar, junto ao rei, pela inocência de "certo homem" cujo nome não é mencionado, acusado de inconfidência no período de estabelecimento do governo dos Braganças. ${ }^{26} \mathrm{D}$. João V teria, em 1712, compartilhado o refeitório com a comunidade do Convento de São Joseph, não querendo comer "senão na tábua nua". ${ }^{27}$

Ao fazerem referência aos nomes e mercês das famílias nobres, os cronistas, além de prestar-lhes homenagens, também cumpriam a função de reconhecer e registrar no papel suas genealogias e direitos. António José Saraiva e Óscar Lopes, em um comentário breve sobre os livros de linhagens portugueses, observam que uma das funções da prática de registrar por escrito os casamentos e as descendências da nobreza era a de "acautelar-se os direitos patrimoniais das famílias fidalgas". ${ }^{28}$ Os três livros que compõem o corpus documental estudado pelos autores são o Livro velho (1270-1280), o Livro do deão (1343) e o Livro de D. Pedro, cuja data de composição é incerta. Apesar de remontarem a séculos

\footnotetext{
${ }^{24}$ PIEDADE, Espelho de penitentes..., p. 236-237.

${ }^{25}$ MARIA, Jesus. Espelho de penitentes..., p. 37-38.

${ }^{26}$ MARIA, Jesus. Espelho de penitentes..., p. 137-144.

${ }^{27}$ PIEDADE. Espelho de penitentes..., p. 227-228.

${ }^{28}$ SARAIVA, António José; LOPES, Óscar. História da literatura portuguesa. Porto: Porto Editora, 2001. p. 85 .
} 
anteriores, segundo os autores eles foram largamente utilizados até o século XVI, por meio de cópias manuscritas que incluíam adições e interpolações. Nieves Baranda nota que a transmissão dos livros de linhagem adentra a historiografia renascentista e barroca, seja por suas cópias manuscritas ou impressas, seja por meio de sua incorporação como lendas ou relações nobiliárquicas em obras históricas. ${ }^{29}$ Cento e cinquenta anos antes de Saraiva e Lopes, Alexandre Herculano já havia apontado que os nobiliários constituíam "uma verdadeira necessidade para regular os direitos e relações entre as illustres famílias". Dois desses direitos, em especial, eram o padroado e a avoenga. ${ }^{30}$ Pode-se considerar, então, esse aspecto comum às crônicas conventuais como uma espécie de "contradom", parte da etiqueta estabelecida por costume em um contexto de "promiscuidade entre religiosos e leigos", na formulação de Joaquim Romero de Magalhães. ${ }^{31}$

Como foi dito anteriormente, ao discorrerem sobre a trajetória das comunidades no decorrer de longos períodos, os escritos aqui analisados evidenciam os modos como elas se posicionaram com respeito a transformações no contexto político. As constantes remissões aos reis terminam por criar imagens determinadas de cada um deles, pois normalmente vêm acompanhadas de informações sobre a situação política do reino, o estado das relações com outras nações e as principais conquistas e derrotas militares, entre outros assuntos. De um modo geral, as crônicas seguem convenções estabelecidas de representação da nobreza. Porém, o fato de algumas dessas obras, notadamente as memórias dos mosteiros clarianos, terem sido escritas em momentos fulcrais da história política portuguesa possibilitou o afloramento, aqui e acolá, de particularidades e dissonâncias entre elas. Em certas passagens, como as que descrevem a derrota de D. Sebastião (1557-1578) no norte da África, o tempo dos Filipes em Portugal e a Restauração de 1640, as especificidades na forma de abordagem ficam mais nítidas.

Com sua redação iniciada em 1630, o Tratado sobre Setúbal constrói suas descrições da monarquia portuguesa nos marcos de uma administração habsburga fragilizada, mas presente. A ascensão de Filipe II de Castela (Filipe I em Portugal,

\footnotetext{
${ }^{29}$ BARANDA, Nieves. Mujer, escritura y fama: la Hespaña libertada (1618) de Doña Bernarda Ferreira de Lacerda. Península. Revista de Estudos Ibéricos, Porto, n. 0, p. 225-239, 2003.

${ }^{30}$ HERCULANO, Alexandre. Memória sobre a origem provável dos livros de linhagens. In: HERCULANO, Alexandre. Composições várias. Lisboa: Aillaud e Bertrand, 19[--].

${ }^{31}$ MAGALHÃES, Joaquim Romero de. A sociedade. In: MATTOSO, José (Org.). História de Portugal: no alvorecer da modernidade. Lisboa: Editorial Estampa, 1993. v. III, p. 469-509.
} 
1581-1598) ao trono português, 50 anos antes, é delineada dentro dos parâmetros normais de sucessão dinástica. Neto de D. Manuel (1495-1521), sobrinho de D. Henrique (1578-1580), o reino teria sido entregue a ele com pouca dificuldade, "posto que não sem mortes de alguns que quiseram resistir". As "alterações" causadas pela entrada das tropas castelhanas incluíram um cerco a Setúbal e ao Convento de Jesus, situado em um ponto vulnerável fora dos muros da vila, que teria recebido um tratamento do duque de Alba que já dava mostras de qual seria a posição da comunidade diante da administração espanhola: o comandante teria ordenado que as tropas não lhe fizessem dano e doado, de seu acervo particular, um crânio das 11 mil virgens, entre outras esmolas. De fato, os trechos que versam sobre os Filipes seguem o mesmo padrão de deferência que os dedicados aos monarcas predecessores, de D. João II a D. Henrique. Começam por narrar como se deu a morte do rei anterior, a ascensão do herdeiro, comentam brevemente os seus casamentos, os nascimentos de seus filhos e enumeram as mercês concedidas ao convento. Também não deixam, quando é o caso, de narrar a presença dos reis dentro do claustro e de se reportar a diálogos que eles teriam mantido com as religiosas. Esses trechos, abusando de tópicos que indicam a quebra de protocolo na relação com o monarca, reforçam a ideia de proximidade e reverência mútua entre este e as sórores. Filipe II, em visita à casa, teria se recusado a deixar que a abadessa e as demais lhe beijassem a mão e, quando a abadessa tropeçou no hábito, a teria tomado nos braços e evitado sua queda. Filipe III, seu filho e sucessor (rei de 1598 a 1621), apesar de permitir que as freiras, postas de joelhos, beijassem sua mão, "levantava a cada uma com muita benevolência". E, a cada momento em que a abadessa ajoelhava para pedir seu auxílio na reforma do monastério, ele a "levantava em seus braços, como se fora Pai, e não Rei”. ${ }^{2}$

Talvez o maior indício do alinhamento da narrativa aos Filipes esteja em um capítulo anterior, dedicado a D. Sebastião. Isso se relaciona com a importância que teve o destino do jovem rei para a afirmação da legitimidade do governo habsburgo em Portugal. Como todos os outros capítulos, esse enumera as mercês concedidas pelo monarca ao convento e a especial devoção que nutria por ele. Porém, também dedica razoável espaço à descrição de seu "desgraçado sucesso e infeliz morte", o que sugere uma preocupação em delimitar as circunstâncias que geraram a crise sucessória que desembocou na união das coroas de Castela e Por-

${ }^{32}$ SÃO JOÃo. Tratado..., fol. 71-72v. 
tugal. O Tratado descreve brevemente a primeira ida de D. Sebastião ao Norte da África, reputando a decisão de adiar o ataque e voltar a Portugal ao baixo número de soldados e à intercessão do "Conselho de Soldados Velhos", o que indica que a autora estava bem informada sobre $\mathrm{o}$ assunto. Relata, em seguida, a segunda tentativa de Sebastião e o seu desfecho trágico: em menor número, os portugueses são rapidamente desbaratados e, na refrega, o rei cai morto após lutar junto a seus "aventureiros de cavalo".

Inicia-se, então, a descrição da saga que envolveu os despojos do rei. Sem quebras de capítulo ou parágrafo, passa-se ao reconhecimento do corpo por seu "moço de câmara", Sebastião de Resende, e por outros nobres que caíram cativos. Eles dão testemunho de que era mesmo de Sebastião o corpo que fora sepultado em Alcácer-Quibir. Em seguida, o relato conta a passagem do corpo para Ceuta, doado por "el hamet" (Mulay Ahmad) a Filipe II, e seu posterior translado até o Reino, tarefa confiada ao duque de Medina-Sidônia. Nesse ponto, a crônica descreve o evento grandioso que foi a transferência do corpo de Faro, no Algarve, até o Mosteiro de Belém. $\mathrm{O}$ ataúde, levado por mulas, passou por diversas vilas e cidades, "e em cada uma destas terras os iam a receber todos os religiosos, povos e justiças na forma que é costume receber aos Reis vivos, porém as festas eram de tantas lágrimas, prantos e soluços como pedia a ocasião". Em meio ao caminho, a marcha solene se deteve em Évora e Almeirim, onde o esquife de Sebastião juntou-se aos de D. Henrique e de infantes filhos de D. Manuel e D. João III (reinado 1521-1557). Por fim, o corpo chegou a Lisboa, onde, com a pompa e circunstância devidas, foi enterrado junto a seu pais e avós. A versão do Tratado segue o rei até seu sepultamento no Mosteiro dos Jerônimos, uma das cerimônias fúnebres de uma longa série iniciada ainda em 1578, semanas depois das primeiras notícias de Alcácer. ${ }^{33}$ A narrativa passa pelo que Lucette Valensi chamou de suas "exéquias reiteradas" - as inúmeras diligências de Filipe II no sentido de reforçar a ideia de que o rei estava morto e enterrado, e não expiando seus pecados disfarçado de mendigo ou celebrando no paço de Prestes João, à espera do momento oportuno para voltar. ${ }^{34}$

\footnotetext{
${ }^{33}$ SÃO JOÃO. Tratado..., fol. 65v-67v.

${ }^{34}$ VALENSI, Lucette. Fábulas da memória - a batalha de Alcácer Quibir e o mito do sebastianismo. Rio de Janeiro: Nova Fronteira, 1994.
} 
Para reforçar a validade do relato - o que sugere o quanto ela era passível de questionamento à época -, a madre Leonor diz ter consultado "livros e papéis autênticos e escritos por pessoas dignas de muita fé e crédito". Uma delas foi Henrique Correia da Silva, alcaide-mor de Tavira e testemunha do longo cortejo fúnebre que atravessou Portugal, com quem a autora teria conversado e se informado "por mais certeza e crédito" do que escreveu..$^{35}$ Afora isso, ela justifica por seu próprio parentesco o acesso a testemunhas especiais e a papéis que "declaram na forma da verdade": seu pai, D. Rodrigo de Castro Barreto, foi um dos nobres que pereceram junto a D. Sebastião no Marrocos. Consultas a testemunhas diretas, acesso a papéis e livros "autênticos", ligação filial com um dos mártires da grande derrota portuguesa - seriam esses expedientes utilizados pela autora para situar seu texto em um debate mais amplo sobre o desfecho do rei Desejado? Jacqueline Hermann chamou a atenção para a relação dialógica estabelecida entre textos e autores que trataram do tema desde os primeiros momentos após o massacre do exército português. Hermann sugere a conformação de uma "guerra de discursos" entre esses escritos, de tal modo complexa que seu estudo aprofundado revelaria lugares de poder e mecanismos de afirmação próprios do Estado moderno, mesmo que "apegado a fórmulas e projetos herdados da Baixa Idade Média", tais como a "guerra santa" ou o "rei guerreiro". A autora afirma que, em meio ao debate, esses discursos estiveram mais interessados pelo "lugar ocupado por cada um dos produtores [das] versões" do que por uma busca desinteressada da "verdade". 36

Não é possível saber ao certo se de fato Leonor de São João acreditava na versão que narrava. De qualquer modo, esta atendia aos interesses da casa reinante, da qual emanavam as disposições que garantiam o bom funcionamento do convento onde foi abadessa. Uma comparação com a Notícia sobre o Convento da Madre de Deus pode ser útil para iluminar mecanismo semelhante em um contexto temporalmente próximo - mas substancialmente distinto - daquele em que se iniciou a redação do Tratado de Setúbal.

A redação da Notícia foi iniciada, a confiar no próprio relato, em 1639, em um ambiente de descontentamento aberto contra o reinado de Filipe IV de Cas-

\footnotetext{
${ }^{35}$ SÃO JOÃO. Tratado..., fol. 68.

${ }^{36}$ HERMANN, Jacqueline. El Ksar El-Kebir. Narrativas e história sebástica na batalha dos três reis. Marrocos, 1578. História: Questões \& Debates, Curitiba, n. 45, p. 11-28 [p. 25], 2006.
} 
tela (rei de Portugal de 1621 a 1640). Conforme se observou anteriormente, nela os monarcas do passado são lembrados por sua participação em momentos cruciais da fundação. Os Filipes, ao contrário, recebem pouca ou quase nenhuma menção. As referências aos reis são mais diretas e elogiosas até a época de D. Sebastião. Para períodos posteriores, o que surgem são comentários enviesados, que sugerem uma atmosfera de insatisfação com o tempo presente. Por exemplo, em conversa sobre a festa de Santa Auta e sobre como ela já havia sido mais venerada no passado, uma das religiosas se queixa do pouco que era "conhecida e festejada", ao que outra replica dizendo que "não era assim em verdade no tempo em que este Reino tinha Reis que eram devotíssimos da Santa, e lhe faziam grandiosas solenidades em o seu dia”. Comentários sobre as relíquias em posse do convento são feitos em tom semelhante, em uma lamentosa comparação entre passado e presente. Nessa passagem, aparece, como no Tratado de Setúbal, o tópico do príncipe que se rebaixa diante das religiosas, mas dessa vez trata-se de D. João (1537-1554), pai de D. Sebastião. ${ }^{37}$

Os Filipes são citados nominalmente em algumas breves passagens. Na primeira delas, Filipe II surge como intercessor em uma questão envolvendo freiras flamengas fugidas de Flandres, aparentemente por questões de perseguição religiosa. Em outra, o mesmo rei é fonte de atribulações para uma das religiosas do convento. Sóror Constança de Jesus - de Gusmão, no século - era filha de D. Afonso de Portugal, conde de Vimioso (1519-1579), morto em Alcácer junto com D. Sebastião. Seu irmão, D. Francisco, que sucedeu o pai no título, havia bandeado para o lado de D. António, prior do Crato (1531-1595), durante a crise sucessória desencadeada pela morte de D. Henrique. Por esse motivo, Constança de Jesus foi presa e enviada à Espanha a mando de Filipe II, juntamente com a condessa sua mãe e mais sete irmãs. De volta a Portugal, ela e as irmãs decidiram tomar hábitos em conventos "com grande brevidade [...] antes que el-rei entendesse no negócio de seu Estado". A Constança coube o Convento da Madre de Deus, onde foi abadessa por quatro vezes. ${ }^{38}$ Os lugares e papéis ocupados pela família de Constança de Jesus, que, malgrado ter caído em desgraça à ocasião da derrota de D. Antônio, continuou a integrar os quadros da administração central

\footnotetext{
${ }^{37}$ Notícia..., fol. 20-v.

${ }^{38}$ Notícia..., fol. 81-82.
} 
do reino e da hierarquia eclesiástica, ${ }^{39}$ fornecem elementos para compreender ao menos parte das redes de relações que permearam a política ibérica no período. Uma política que emerge bem menos compartimentada que o sugerido por certos paradigmas de distinção nacional estabelecidos desde o século XIX. ${ }^{40}$

Outra religiosa retratada na Notícia, cuja memória dá indícios para se rotear o lugar social do convento - ou a posição construída pela crônica para ele -, é sóror Maria da Conceição. O trecho em que sua história é contada foi escrito em 1644, quatro anos após a ascensão de D. João IV ao trono português. Nele, revela-se outro tipo de relação entre religiosas e rei, mais próxima daquela intimidade que marcou a convivência com os monarcas de outrora e distinta da que é endereçada aos Filipes de Castela. "Mui nobre" e filha de pai estrangeiro, Maria da Conceição era, segundo a autora, conhecida por seus dons de presciência. Em uma ocasião, prevendo a derrota de D. João em um embate contra castelhanos, teria pedido às demais religiosas que escrevessem a parentes seus que iam ao paço, alertando que "se não havia de conseguir o intento". A narrativa faz ainda menção a outro recado seu ao rei, pedindo que "mandasse dizer todos os dias três missas ao Anjo S. Miguel, custódio de el-Rei e do Reino”. Por essa época, o convento também seria responsável por lavar e consertar os corporais da capela real. ${ }^{41}$ Nesses trechos mais adiantados da redação da Notícia, a figura do soberano aparece reatada com a casa conventual e suas religiosas. Não é mais aquele rei distante e ausente, digno apenas de queixas e lamentações. Está ao alcance das religiosas, e tanto pode ouvi-las opinar sobre matérias diversas quanto encarregá-las de funções importantes, como a de conservar os panos que cobrem o altar da sua capela. É possível dizer que o longo tempo tomado pela redação da Notícia possibilitou a recuperação, ao final da própria crônica, de um tom laudatório considerado no início como parte de um passado perdido. Dessa forma, a obra como um todo é testemunho de viragens políticas da história portuguesa, e sua elaboração está com elas envolvida.

\footnotetext{
${ }^{39}$ Também eram seus irmãos João de Portugal, que foi bispo de Viseu (c. 1553-1629), e Nuno Álvares de Portugal, que governou o Reino (1565-).

${ }^{40}$ Cf. SILVA, Ana Cristina Nogueira da; Espanha, António Manuel. A identidade portuguesa. In: MATTOSO, José (Org.). História de Portugal: o Antigo Regime. Lisboa: Editorial Estampa, 1992. v. 4, p. 19-47 [esp. p. 19-25].

${ }^{41}$ Notícia..., fol. 133-135v.
} 
O Tratado de Setúbal também sofreu modificações posteriores. Seus últimos adendos datam do ano 1646. Por isso, a exemplo da Notícia, o texto trata da ascensão de D. João IV em 1640, mas no final do manuscrito, no trecho dedicado à memória dos abadessados, e não no rol dos reis benfeitores da casa. É flagrante a descontinuidade narrativa entre os reinados de Filipe IV e do duque de Bragança. Na costura que faz para retomar o assunto da sucessão monárquica, é possível perceber seu esforço de resumir em poucas linhas o muito que se passou entre o último Filipe português e a instalação da Dinastia Brigantina. Ao tratar da ascensão de D. João IV, refere-se ao "miserável estado" a que Portugal chegara no período anterior, ${ }^{42}$ sem entrar em detalhes, talvez expressando a dificuldade de compatibilizar relatos aparentemente discrepantes nas partes inicial e final do manuscrito. Limita-se a mencionar a "santa e valorosa resolução" tomada pelos portugueses, qual seja, a da aclamação de D. João de Bragança. Assim como fez no momento de incensar os Filipes, o Tratado volta ao passado e à genealogia para situar a dinastia nascente, redimensionando o tempo em que Portugal ficou unido a Castela pela dupla coroa. O tom laudatório aos Habsburgos já não apresenta mais as mesmas cores. A reverência destinada aos Filipes se transfere aos Braganças de maneira abrupta, deixando ao tempo dos primeiros "as desgraças altas", quase que uma deixa para a recuperação, pelo próprio duque de Bragança, da tradição mítica da monarquia portuguesa. ${ }^{43}$ Se essas mudanças no texto respondem a uma preocupação editorial, demonstrada pela autora na medida em que persegue padrinhos ou simpatizantes da sua publicação, não é possível afirmar. Outra possibilidade de explicação reside na necessidade premente de criar laços com o novo governante, abrindo caminho para o favorecimento do convento nas decisões e emanações régias.

O desenrolar dessas narrativas ilustra o caráter das crônicas como discursos associados à dinâmica das interações entre as casas religiosas e seu contexto, assim como à dinâmica da política interna travada no seu interior. Não é apenas quando tratam da figura do rei que as memórias não se furtam a, aqui e ali, deixar entrever a heterogeneidade de suas afiliações e composição. Em Setúbal, uma freira teria pedido a Filipe II permissão para orar pela alma do prior do Crato; em Xabregas, outra era tia de Diogo Soares (c. 1600-1649), influente nobre português

\footnotetext{
${ }^{42}$ SÃO JOÃO. Tratado..., fol. 289v.

${ }^{43}$ SÃO JOÃO. Tratado..., fol. 289v-290v.
} 
ligado à administração castelhana que ocupou o cargo de secretário de Estado do Conselho de Portugal em Madri e, após a aclamação de D. João IV, caiu em desgraça no Reino. ${ }^{44}$ Antonio da Piedade expressa julgamento ambíguo ao referir-se a D. Raimundo de Lencastre (1620-1666), quarto duque de Aveiro, que nos idos de 1660 aliou-se a Castela, onde se tornou comandante militar contra Portugal. O duque é, ao mesmo tempo, tido como benfeitor que deu continuidade à estima e proteção da Casa de Aveiro à província da Arrábida e qualificado como tendo "esquecido do que mais se devia lembrar, que era o brio Português" ${ }^{5}$ Como argumenta Ramada Curto, uma análise detalhada da relação entre sujeitos que a historiografia consagrou como antagonistas, que dê especial atenção, sobretudo, aos tempos anteriores a 1640 que separou suas trajetórias e ensejou futuras leituras apaixonadas do episódio, pode colocar em outros termos questões relativas à fidelidade ao rei, patriotismo, nacionalismo etc. ${ }^{46}$

Um breve exame dos modos como as crônicas da Arrábida tratam do período de vigência da união ibérica e da posterior Restauração também serve de ilustração para as ideias apresentadas. Não dispomos de informações precisas sobre os intervalos de tempo em que os freis Antonio da Piedade e Joseph de Jesus Maria escreveram as memórias da província. É de se supor que começaram suas composições alguns anos antes das datas de publicação, respectivamente 1728 e 1737. Nas décadas de 1720 e 1730, Portugal desfrutava de um relativo equilíbrio nas relações internacionais, contando principalmente com alianças com Roma e a Inglaterra, mas também mantendo com a Espanha relações menos conflituosas que as do século XVII. ${ }^{47}$ Essa atmosfera parece ter-se refletido na escrita de ambas as crônicas, nas quais é em geral notória a raridade de tomadas de posição política e de referências a tensões e conflitos entre os reinos ibéricos, mesmo quando versam sobre o período que se estende de 1580 a 1640. Relativamente à extensão das obras, os Filipes e seu governo são citados com bem menos frequ-

\footnotetext{
${ }^{44}$ Notícia..., fol. $164 \mathrm{v}$.

${ }^{45}$ PIEDADE. Espelho de penitentes..., p. 89-91.

${ }^{46}$ CURTO, Diogo Ramada. A Restauração de 1640...

${ }^{47}$ Portugal, Lisboa e a Corte nos reinados de D. Pedro II e D. João V. Memórias históricas de Tristão da Cunha de Ataíde, 10 conde de Povolide. Introdução António Vasconcelos de Saldanha e Carmen M. Radulet. Lisboa: Chaves Ferreira Publicações, 1990. p. 324-438; Alexandre de Gusmão e o Tratado de Madrid. Documentos organizados e anotados por Jaime Cortesão. Rio de Janeiro: Ministério das Relações Exteriores, 1952. t. I.
} 
ência que nas memórias dos Conventos de Jesus e da Madre de Deus e, quando o são, a tônica é mais fleumática. Nas passagens em que é feita menção a nobres espanhóis, o argumento em geral gira em torno dos interesses de determinado convento e/ou da província como um todo. Em relato sobre visita de Filipe III (1598-1621) a Portugal, em 1619, Antonio da Piedade discorre sobre a pompa da ocasião e o grande poder do monarca, mas centra-se nos esforços do provincial Fernando de Santa Maria $(† 1638)$ em dele obter auxílio para mudar o Convento de Salvaterra para um sítio menos insalubre. Em resposta ao pleito, o "piedoso" rei teria feito doação para a construção de edifício em outro local. ${ }^{48}$ Joseph de Jesus Maria, ao tratar da biografia do mesmo frei, conta que, quando da chegada ao reino de D. Diego de Silva y Mendoza para assumir o cargo de vice-rei (que ocupou de 1617 a 1621), os prelados superiores das diversas ordens foram cumprimentá-lo. Por insistência deste, frei Fernando, ele próprio de ascendência castelhana nobre, tornou-se seu confessor. Diz o autor que o frei era também conselheiro espiritual da infanta de Portugal D. Catharina, duquesa de Bragança (1540-1614), e de outros membros da aristocracia lusa. Circulava, dessa forma, entre as elites de ambos os reinos. ${ }^{49}$ Um exemplo adicional é o relato referente à celebração de capítulo em 1589. O impedimento, por ordem de Filipe II, de que fosse escolhido como provincial um padre português teria gerado reações entre os vogais. A situação, considerada "nociva à Província pelas alterações, em que andava o Reino", foi apaziguada pela eleição de certo frei que "nem era português nem filho da Província", não tendo "nenhuma inclinação particular a esta, ou àquela Coroa.". 50

É forçoso notar, no entanto, que o tom da narração muda, tornando-se mais tendente a expressar juízos políticos quando as crônicas tratam de acontecimentos especialmente relevantes do período aqui enfocado. No primeiro volume da Chronica da Arrábida, um trecho razoavelmente longo é dedicado a D. Sebastião e à expedição ao Norte da África. Por um lado, as referências ao rei enfatizam seu zelo religioso, "carinhosos desvelos, e gratuitas liberalidades" em relação à província. Por outro, apontam sua falta de aptidão para o governo do reino, expressa nas suas constantes ausências do paço, "temeridades que obrava, e perigos a que

\footnotetext{
${ }^{48}$ PIEDADE. Espelho de penitentes..., p. 131-132.

${ }^{49}$ MARIA, Jesus. Espelho de penitentes..., p. 58-70.

${ }^{50}$ MARIA, Jesus. Espelho de penitentes..., p. 81-82.
} 
se expunha", características que explicariam as decisões que levaram ao desfecho de Alcácer-Quibir. ${ }^{11}$ Um frade da província, Salvador da Cruz (†1578), teria se manifestado publicamente, em sermão diante do monarca, contra a expedição, na qual ambos acabaram perecendo. ${ }^{52}$ Também o episódio da aclamação do prior do Crato é relatado com certo detalhe por Antonio da Piedade, que sugere que este tinha o apoio da maior parte dos padres da Arrábida. ${ }^{53}$

Quando a narrativa de Jesus Maria chega a 1640, torna-se comemorativa e até ufanista. De qualquer modo, ainda focaliza o "espírito profético" de dois arrábidos, que teriam influenciado a disposição de fidalgos portugueses envolvidos no esforço de instauração da Dinastia de Bragança, e a mediação de outro, nos conflitos após a aclamação de D. João IV. D. Antonio Mascarenhas e D. Miguel de Almeida, incertos quanto à empreitada a que se lançavam, teriam procurado aconselhar-se com frei Antonio das Chagas, que os assegurou de seu sucesso. Ainda outro religioso, do Convento de São Joseph de Ribamar, teria lhes dito: “O baraço está na garganta, é necessário sacudi-lo, e estou certo, que não se hão de afogar." Depois da aclamação, frei Ambrosio da Conceição, "muito venerado" pelo então governador da Fortaleza de São João da Barra, D. Fernando de la Cueva, o teria persuadido a desistir da resistência e mediado a devolução da fortaleza aos portugueses. ${ }^{54}$ É relevante observar como, nessa parte da crônica, Joseph de Jesus Maria conecta-se com uma rede de histórias do evento, citando inclusive a Restauração de Portugal prodigiosa, de D. Gregório de Almeida (1643). Justifica a "breve digressão" argumentando não ser justo que "deixemos de trazer à memória a felicidade, que [...] gozou este Reino com a gloriosa aclamação do Sereníssimo Rei D. João IV". Adiante, o texto ainda faz menção aos ânimos "facilitados [...] para as discórdias" e às ingerências do rei no sentido de reprimir inconfidentes e indivíduos - inclusive pregadores - que insuflassem as tensões. ${ }^{55}$ Mas em geral prossegue deixando o assunto para as "muitas, e doutas penas" que sobre ele discorreram, voltando-se para outros aspectos da trajetória da província.

\footnotetext{
${ }^{51}$ PIEDADE. Espelho de penitentes..., p. 547-556.

${ }^{52}$ PIEDADE. Espelho de penitentes..., p. 561-565.

${ }^{53}$ PIEDADE. Espelho de penitentes..., p. 691-693.

${ }^{54}$ MARIA, Jesus. Espelho de penitentes..., p. 126-127.

${ }^{55}$ MARIA, Jesus. Espelho de penitentes..., p. 141.
} 
Para concluir a breve análise feita neste artigo, espera-se ter evidenciado como, a par de objetos mais diretamente associados à vivência religiosa e à história institucional das ordens e conventos, a leitura das crônicas monásticas permite explorar as vinculações políticas dessas comunidades e os modos variados como se relacionaram com determinados processos históricos, em especial no que respeita a mudanças nas esferas de poder. Permite, na expressão de Isabel Ferreira da Mota, "ligar a história das instituições à vida mutável da sociedade e do Estado". ${ }^{6}$ Essas fontes são a cristalização de redes de relações, em parte decorrentes da composição nobiliárquica dos mosteiros, mas não apenas isso. Devem ser tratadas como expressão da interação desses grupos religiosos com interlocutores da sociedade circundante e com circunstâncias particulares. Vistas dessa forma, elas fornecem elementos para compreender o universo português do Antigo Regime de um modo mais rico e pluridimensional.

${ }^{56}$ MOTA, Isabel Ferreira da. A Academia Real da História. Os intelectuais, o poder cultural e o poder monárquico no século XVIII. Coimbra: Edições Minerva, 2003. p. 21. 